\title{
Deepening ICT integration through multilevel design of Technological Pedagogical Content Knowledge
}

\author{
Ching Sing Chai • Elizabeth Koh • Cher Ping Lim • \\ Chin-Chung Tsai
}

Received: 15 October 2013/Revised: 7 January 2014/Accepted: 18 February 2014/

Published online: 28 March 2014

(C) Beijing Normal University and Springer-Verlag Berlin Heidelberg 2014

\begin{abstract}
This paper reflects upon the ICT integration efforts of the last two decades. It reviews major frameworks that have been employed to make sense of ICT integration, and argues for a more significant change among educators at all levels given the pervasiveness of ICT in today's society. An expanded version of the Technological Pedagogical Content Knowledge is proposed as a theoretical framework for creating new knowledge and innovative practices for ICT integration in educational settings.
\end{abstract}

Keywords ICT integration - TPACK · Design knowledge

\section{Introduction}

The proliferation of personal computing devices and the World Wide Web have permanently changed how people live, work, and communicate in today's society. In addition, today's workplace puts high demands on workers' ability to generate innovative solutions. Such socioeconomic and technological transformations have presented educational institutions with the challenges of what learning outcomes to develop, and how these outcomes could be developed. Researchers from the East and the West alike have called for a reconsideration of the purpose of education. An emerging consensus in response to the knowledge society is to raise the teaching of

\footnotetext{
C. S. Chai · E. Koh

Nanyang Technological University, Singapore, Singapore

C. P. Lim

Hong Kong Institute of Education, Tai Po, Hong Kong

C.-C. Tsai $(\bowtie)$

National Taiwan University of Science and Technology, Taipei, Taiwan e-mail: cctsai@mail.ntust.edu.tw
} 
design-oriented cognition as a means of knowledge creation (for example, Bereiter and Scardamalia 2006; Chai and Lim 2011; Cross 2006; Tsai et al. 2013). Design thinking not only demands that learners grasp current understandings represented in existing verified knowledge, but that it also pushes learners to innovate. Design then treats all knowledge as tentative epistemic resources for further improvement and refinement, and builds on scientific discovery and artistic expressions to create new entities; it is a form of knowledge creation activity that is commonly mediated by artifacts. The affordances of ICT, including the multimodal, communicative, and revisable nature of the digital artifacts created through ICT, support design and knowledge creation activities. ICT in essence comprises tools created for work. Jonassen (2000) shows how ICT could be used as cognitive tools, while Tsai (2004) shows how ICT could be employed as epistemic tools. This paper will show how ICT could also be used as design tools. These perspectives of using ICT are complementary in essence, and by leveraging them, we envision deeper work on ICT integration through its pedagogic use.

In line with our conception of ICT as a design tool, ICT integration designs need to consider the knowledge bases, content, pedagogy, and technology as well as their interactions (Koehler and Mishra 2009). This Technological Pedagogical Content Knowledge (TPACK) framework enables creative and successful designs for ICT integration in the classroom. Although originally developed for teachers in the classroom, we expand on this framework and posit a broader approach to creating new knowledge and innovative practices for ICT integration for educators.

In the following sections, we first review major research efforts to study ICT integration in the last two decades, and the associated issues and challenges. The past findings and issues set the stage for a review of the existing approaches to integrating ICT. This is followed by the introduction of an expanded TPACK framework which may deepen ICT integration in educational institutions.

\section{Major studies in ICT integration}

An important perspective for understanding the role of ICT in education has been to view ICT as tutor, tool, or tutee (Taylor 1980). Using computers as tutors is exemplified by the instructionist oriented tutorial software or the teaching clips on YouTube and "flipped" classrooms. Typically, the computers present information and provide practice and feedback for the learners. The computer as tool emphasizes the computing power of computers, which releases the users to focus on higher order tasks such as pattern recognition and prediction. Jonassen et al. (2008) highlighted many examples of how various computer software packages can function as cognitive tools to engage learners in constructivist-oriented learning. Using computers as tutees allows the users to teach/program the computers to perform actions that represent learning of specific subject matter, as in for example, the constructionist-oriented use of Scratch to engage students in learning-by-design (see Baytak and Land 2011). These three ways of employing computers in the classroom are not mutually exclusive. Teachers may mix and match the roles of computers in response to different students' learning needs. 
Except for the use of computers as tutor, which is usually coupled with using computers for drill-and-practice, the latter two forms of pedagogical use of computers place high demand on the teachers' skills of designing the learning environment and scaffolding students' emerging understanding. While the use of computers as tutor seems to be welcomed by teachers, many education researchers have rather advocated their use as tools or tutee as, in these roles, they are believed to facilitate students' higher order thinking and collaborative learning. Such constructivist/constructionist-oriented use of ICT is perceived as promoting twentyfirst century competencies (Voogt and Roblin 2012). However, the ICT supported constructivist or constructionist-oriented pedagogies are yet to be a common phenomenon in the classroom (see Lim et al. 2013; Voogt et al. 2013a).

Two major affordances of ICT are the computation power and the communication channels it provides for users. For the former, users are given the power to perform complex operations on various forms of data (numerical, visual, audio, etc.), both effectively and efficiently. For the latter, communication of information through the World Wide Web enables the speedy spread of and access to information. When these two affordances interact, ICT becomes an indispensable tool for knowledge workers. Governments all around the world have been quick to recognize the economic, social, and educational implications of ICT, and plans for integrating ICT into classroom teaching and learning have been formulated and implemented. Such policies also help to push educational research on ICT integration. However, the research to date still indicates that despite the huge amount of fiscal provision in equipping schools and training teachers, there are gaps in actual usage in the classrooms, and the enhancement of learning outcomes remains questionable (Blackwell et al. 2013; Lim et al. 2013; Voogt et al. 2013a). As teachers are the key to most educational reforms, some of the earlier studies devoted much attention to understanding the relationships between teachers and technology-enhanced innovative pedagogies (e.g., Zhao et al. 2002).

In the Apple Classroom of Tomorrow (ACOT) project, Sandholtz and Reilly (2004) used the grounded approach to describe five stages of ICT integration in the classroom that included entry, adoption, adaptation, appropriation, and invention. Teachers who had been provided with personal computers progressed from learning to use technology to innovating with technology. Zhao et al. (2002) also employed the grounded approach and reported that other than acquiring technical skills, teachers need to work through the messy process of integrating ICT into their classroom teaching and learning. Whether or not a new practice in using ICT can become a more permanent part of the school teaching, and learning ecology is dependent on the interactions between the innovative practice, the innovator, and the context. Lim (2007) adopted the activity theory (see Engestrom 1999) to analyze the conditions for ICT integration based on the Singapore school experience. He identified multiple contradictions and highlighted that classroom management, orienting activities, scaffolding, and supportive school policies are conducive conditions for effective ICT integration to promote higher-order thinking. In sum, the interaction between teachers' attributes akin to innovating and designing, and contextual variables such as access and support for the technologies and the 
envisioned pedagogies are the major factors that determine the success or failure of ICT integration in educational institutions.

Focus on the teachers' attributes has led to another theme-teachers' perceived barriers to ICT integration (Ertmer 1999; Pelgrum 2001). Ertmer (1999) claimed that first-order barriers may include training teachers' technological knowledge (TK), availability of equipment, time constraints for lesson planning, and lack of technical support. The second-order barriers are identified as teachers' pedagogical beliefs. Ertmer (2005) subsequently proposed that teachers' beliefs are likely to be the more formidable barrier. These beliefs could be about technology, pedagogy, students, and even epistemology. Beliefs could magnify or diminish the first-order barriers and are more deeply rooted, and thus difficult to change. It is, therefore, necessary to reshape teachers' beliefs about ICT integration during professional development activities. Some researchers have empirically identified teachers' beliefs as a predictor of their intention to use ICT (Chai 2010; Sang et al. 2010). However, even teachers who espouse relevant beliefs (for example, constructivist pedagogical beliefs) could be practicing knowledge transmission when they use ICT (see Lim and Chai 2008). More recently, Hsu and Kuan's (2013) study of Taiwanese teachers $(N=3652)$ in more than two hundred schools through multilevel modeling revealed that teachers' beliefs and hours of training predict their ICT integration proficiency. Important school level predictors are connection to the Internet, the availability of projectors, and the stability of the computers. Their study indicates that both the first- and second-order barriers continue to shape teachers' use of ICT, and hence, ICT integration.

In addition to these barriers, Tsai and Chai (2012) have pointed out that teachers' lack of design thinking constitutes the third-order barriers to ICT integration. Teachers with design capacity are more likely to be willing to search for ways of circumventing the barriers and to design pedagogical solutions to fulfill the demands of the twenty-first century workplace. Goktas et al. (2013) recent investigation of Turkish primary school use of ICT pointed toward the same conclusion. Tsai and Chai's (2012) proposal is linked to the earlier studies on the innovators (Sandholtz and Reilly 2004; Zhao et al. 2002), but they point out more concretely that teachers need design thinking. TPACK (Mishra and Koehler 2006) may serve as a framework to make sense of design thinking. TPACK is based on the concept of pedagogical content knowledge (PCK) by Shulman (1986, 1987). It adds TK, and argues that teachers require three core knowledge components as well as the knowledge of the interacting components between and among these bodies of knowledge.

\section{Reviewing the purpose of ICT integration}

The above review shows that integrating ICT is a complex and demanding endeavor, and decades of work has resulted in uneven implementation with limited innovators and a host of barriers (Jamieson-Proctor et al. 2006; Voogt et al. 2013a). If the purpose of integrating ICT into classroom teaching and learning is to promote the learning of verified knowledge (to help students score well in examinations), 
then the traditional method of providing good lectures and adequate guided practices would suffice. How many teachers would bother to battle with the host of variables associated with the teachers, the technologies and the sociocultural environment just to get the students to achieve better grades using ICT? Furthermore, these variables are dynamic in nature and can hardly be resolved once and for all. Technologies are ever advancing, and access to new technologies has to be organized every few years. Pedagogical innovations such as Webquest (Dodge 2001) command attention for a few years before requiring further innovation. Zhao et al. (2002) have highlighted the issue of the ecological validity of ICT-related innovative teaching. While the constant perturbations of ICT-based teaching come and go, the skillful teachers continue to prepare students for examination that are practically not associated with ICT, employing the tried-andtested traditional methods. At best, they may sometimes use computer-based tutorial software and assign students to do automated drill-and-practice on the computers. In view of this, Voogt et al. (2013a) have pointed out the need to innovate assessments. However, whether a new assessment system would address associated challenges is still a big question mark.

Given the above issues, the rationale of integrating ICT in schools has to be constantly reviewed to create deeper and pedagogically sound knowledge of these issues. Facer (2011) has identified several ICT integration trends that are highly possible. ICT is likely to become more accessible and advance with ever increasing affordances (e.g., the emergence of Web 2.0 environments and sophisticated learning analytics) to exert a deeper and wider impact on how we work and live, and thus challenges established teaching practices in schools. ICT cannot be kept out of the classroom in the current education environment as the economic viability of today's society is largely dependent on it. While many would agree with this position, it seems that this only warrants ICT skills training rather than the integration of ICT for subject matter learning. Most schools today have such programs. Stronger reasons for ICT integration are needed.

Another important reason would be that ICT is a cognitive and epistemic tool for knowledge workers. Many professions are greatly enhanced by the use of ICT for productivity and knowledge creation purposes. Health workers, financial organization employees, engineers, and statisticians, for example, all rely on specialized ICT software to conduct their business. ICT has also exerted tremendous influence on the consumer lifestyle and sociopolitical issues (e.g., the Arab Spring). More importantly, today's youth actively participate in online special interest groups and learn on their own to create meaningful digital artifacts (e.g., online novels, games, applications, etc.). This trend has been characterized as the new culture of learning (Thomas and Brown 2011). ICT is an integral part of every individual's professional and daily life; the use of ICT cannot be ignored, especially in schools. For each trend identified and explained above, a response is required from schools.

Content knowledge (CK) of the professional fields is well-integrated in the professional use of ICT. Professionals use ICT as cognitive and epistemic tools to process data and information to generate knowledge and to solve problems. Their content expertise allows them to manipulate and interpret the data mediated by ICT and find solutions to emerging questions (Jonassen 2000). There are few professions 
today that do not rely on ICT to advance knowledge. The question for schools then is: "Why do teachers find it hard to integrate ICT in content teaching?" The answer may lie in the epistemic processing of school knowledge that is often associated with schooling for examinations (Macdonald and Hursh 2006). The divide between schools and the workplace thus needs to be addressed; hence the positioning of school as a cultural entity (Tsai et al. 2013).

Fostering the design-oriented epistemic stance and creating the pedagogy of how to use ICT as tools to support students in constructing, creating and/or refining CK is what today's educators are promoting as the key focus for the use of ICT (Bereiter and Scardamalia 2006; Tsai et al. 2013; Voogt et al. 2013a). In other words, the integration of ICT should be geared towards cultivating twenty-first century competencies, and this is where teaching practices have been found lacking. The new culture of learning reported by Thomas and Brown (2011) demonstrates that without the teachers or formal curriculum support, a small number of highly motivated and self-directed learners are still demonstrating twenty-first century learning. This culture among teenagers is likely to spread, and it will increasingly challenge traditional pedagogies as learners become more critical and disengaged from passive learning methods in schools. To prepare students for the workforce, and to respond to the emerging youth culture of learning, educators need to resolve the dilemma between knowledge acquisition and knowledge creation, instructivist and constructivist pedagogy, pen-and-paper testing for verified facts and performance assessment for collaborative co-construction. These objectives related to education need not be at two ends of the dichotomy; the latter may build on the former. However, given the limitations of time allocation for $\mathrm{CK}$ in the curriculum and the final placement examinations, many teachers are pushed towards achieving the simpler objectives using the most efficient method.

Current proposals that counter the push are in the direction of enhancing teachers' capacity to design and create TPACK for twenty-first century competencies (Chai et al. 2011; Tsai et al. 2013; Voogt et al. 2013a).

\section{The TPACK framework}

TPACK is an approach to designing ICT integration that recognizes the complex issues that teachers face in the classroom (Mishra and Koehler 2006). Six types of knowledge can be drawn upon to form TPACK. TPACK begins with three foundational forms of knowledge, namely TK, pedagogical knowledge (PK), and CK. However, educators also need to draw upon the intermediate knowledge formed through two interacting types of foundational knowledge to create TPACK. These intermediate forms of knowledge are technological pedagogical knowledge (TPK), technological content knowledge (TCK), and PCK. TPK denotes the PK associated with the use of specific ICT (e.g., how to facilitate learning with discussion forums); TCK denotes technological knowledge embedded with CK (e.g., Google Earth for geography); while PCK refers to knowledge about how to teach certain content to specific groups of students (e.g., using water flow to teach the concept of electric current) (Cox and Graham 2009). 
A teacher who designs inquiry-based learning (PK) employing the geographical features embedded in Google Earth (TCK) would be developing TPACK for geography. In a similar vein, teachers could draw upon any two or more forms of the intermediate knowledge to formulate a particular lesson plan that requires TPACK. Past empirical research employing structural equation modeling (see Chai et al. 2011; Koh et al. 2013) indicates that TPK and TCK are likely to be significant predictors of teachers' TPACK efficacy.

Based on the above example, TPACK may be formed through multiple pathways depending on the breadth and depth of the teachers' existing knowledge; the more knowledgeable an educator, the more easily he/she could formulate an ICTintegrated lesson. If the educator possesses more knowledge of the technology, pedagogy, and content, as well as the interrelated knowledge, he/she will be able to design more appropriate artifacts for ICT in education.

Moreover, the different forms of knowledge have to be acquired/activated or constructed and further reconstructed through design efforts for a specific class with a specific learning history of the subject matter. For any lesson to achieve optimal outcomes, the teachers cannot rely on the standardized application of a pre-designed lesson, but must customize the lesson to suit the students' profile, such as their prior knowledge. In other words, TPACK is an epistemologically dynamic and situated form of knowledge (Mishra and Koehler 2006). TPACK is also in essence knowledge created by design, and therefore is not about the "truth" but about creating satisfying pedagogical solutions of helping students learn for the twentyfirst century workplace. Two major reviews published to date (Chai et al. 2013; Voogt et al. 2013b) have pointed out that research in teacher education generally attests to the efficacies of engaging teachers in learning by design, to build teachers' TPACK. While it has been argued that the twenty-first century workplace demands design-oriented innovative and creative workers, it seems apt that it also demands twenty-first century teachers to be design-oriented creative professionals who can leverage TK and PK for content learning. However, the TPACK research has to date focused almost exclusively on teachers as designers of lessons (Chai et al. 2013). How teachers could benefit from and contribute to TPACK creation have been less researched.

Another limitation of the TPACK framework is that the "context" in question concentrates only on the classroom. The extant literature has begun to pay some attention to unpacking the broader contextual variables influencing TPACK. This is congruent with Tondeur et al. (2008) criticism of studies of ICT integration, which have been very much confined to the classroom levels and have ignored the influences of the larger sociocultural context. For instance, building on the variables that emerged from earlier ICT integration research, Chai et al. (2013) have suggested four categories of contextual variables that influence and are influenced by teachers' efforts in creating TPACK. The physical and/or technological environment obviously contains some basic variables that enable or constrain teachers' design of TPACK. For example, the classroom management strategies to be adopted for an ICT class for teachers who have access to network-based classroom management technology are much simpler than for those teachers who do not have such access. The intrapersonal category accounts for teachers' intra-mental 
variables such as their pedagogical beliefs, attitudes towards ICT, etc. Teachers' with constructivist beliefs have been found to be more inclined to use ICT as cognitive tools (Chai 2010). As TPACK is usually constructed by teacher design teams, the interpersonal dimension could also impact the TPACK development. Group composition and members' patterns of interaction are well known variables that impact group outcomes. Lastly, contextual variables associated with the cultural categories could be education stakeholders' expectations of teaching and the examination-oriented culture.

As discussed, many categories of contextual variables may shape teachers' design decisions. In addition, how these variables influence other educators occupying different positions in the education service is virtually unknown. Therefore, to deepen the understanding of ICT integration, we propose an expanded TPACK framework that considers a wider meaning of "context," such as the inclusion of interpersonal or cultural factors.

\section{The expanded TPACK framework}

In line with Porras-Hernandez and Salinas-Amescua's (2013) theorization, the "context" in TPACK can be delineated in terms of (a) actor, and (b) scope. The actor refers to the stakeholder in the system, who requires some form of TPACK in order to shape ICT integration. The current research on TPACK is confined to teachers as the main subject while ignoring the other actors in the education system. These actors include the student, the curriculum designer, the head of department, the school principal, ministry officers, software designers, parents, and industry partners. These other actors need to understand TPACK so that they can contribute to the design of curriculum guidelines, policies, infrastructure and physical space allocation, etc. in order to achieve ICT integration.

Secondly, we propose that the TPACK framework should expand the scope of its context. Porras-Hernandez and Salinas-Amescua (2013) criticized the research in TPACK as defining the teachers' work context too narrowly, and proposed that researchers should employ Bronfenbrenner's ecological approach (see Bronfenbrenner 2005) to consider how different levels of context could impact on teachers' TPACK. They focused on three levels of Bronfenbrenner's framework, namely the micro-level (i.e., the classroom), the meso-level (i.e., the local community and the educational institution), and the macro level (i.e., the social, technological, and political environments). Their research also attempts to illustrate through the phenomenological approach how teachers view the various context levels.

Bronfenbrenner's ecological approach, also known as the ecological systems theory, provides an influential and systematic scope for TPACK. The ecological approach is a model of human development with the child at the center of the system. It consists of five rings of interconnected systems, namely the microsystem, mesosystem, exosystem, macrosystem, and chronosystem, which shape the child's psyche. Bronfenbrenner (1994) theorized that the microsystem is one immediate environment of the child, e.g., the home, family, or peer group. The mesosystem is the relationship between two or more microsystems, such as the link between home 
and school. The exosystem refers to the linkages between the microsystem, and an environment that the child does not reside in, e.g., the home and the parent's workplace. The macrosystem consists of the wider processes and patterns prevalent in the micro-, meso-, and exosystems such as belief systems, customs, lifestyles, and policy structures. Lastly, the chronosystem emphasizes the passage of time and is a slightly different dimension from the earlier levels. This historical context examines both the change in the child over time as well as the change in the environment in which the child lives.

Bronfenbrenner's ecological system has enlightened many social science researchers, prompting them to look at the different realms of influence that any social phenomenon could be subjected to. In a similar vein, Lim and Hang's (2003) earlier work on ICT articulated four levels of context as Ministry of Education, Education Technology Division (the office within the Ministry in charge of education technology), schools and classrooms. The framework has allowed Lim (2006) to tease out important insights into ICT integration such as highlighting the problems of contradictory relationships between the activity systems that are pegged at different levels. Although their research does not explicitly mention Bronfenbrenner's ecological approach, we can recognize the different levels at play, i.e., the macro-level (the Ministry), the exo-level (the Division), the meso-level (the school, consisting of the different classrooms), and the micro-level (the classroom).

Putting our "contexts" of actor and scope together, we propose that research on TPACK, and thus on ICT integration, can be conceptualized at five levels as depicted in Fig. 1. This expanded TPACK framework argues that TPACK creation is a multilevel context with actors of different designations. Although incorporating Porras-Hernandez and Salinas-Amescua's (2013) perspectives of actor and scope, it differs from their paper in that we argue for the inclusion of all five levels of Bronfenbrenner's ecological approach. In particular, we will subsequently elaborate that the exo- and chrono-levels, which were left out of Porras-Hernandez and Salinas-Amescua's (2013) research, are important missing gaps in the study of ICT integration.

Starting from the center of Fig. 1, the TPACK framework examines the actorthe teacher, curriculum designer, principal, or software engineer-who requires TPACK for the design of ICT integration. This actor can draw upon the six forms of knowledge to create TPACK. We also recognize that at each level, there are different educators who can draw on TPACK, not only the teacher. This actor's immediate environment is the micro-level. Using the example of the teacher as the actor of focus, the immediate environment is the classroom. The educator at this level could be the teacher who can draw on TPACK to create ICT integration. Many studies of TPACK and ICT integration have solely focused on this micro-level. However, teachers are not usually the decision makers beyond the micro-level. There is therefore a need to consider the other levels and the major decision makers' perspectives within each level, rather than confining the perspective to the teachers alone.

The meso-level concerns the relationships and patterns in the environments in which the teacher is involved such as the classroom and the teacher's home or two 


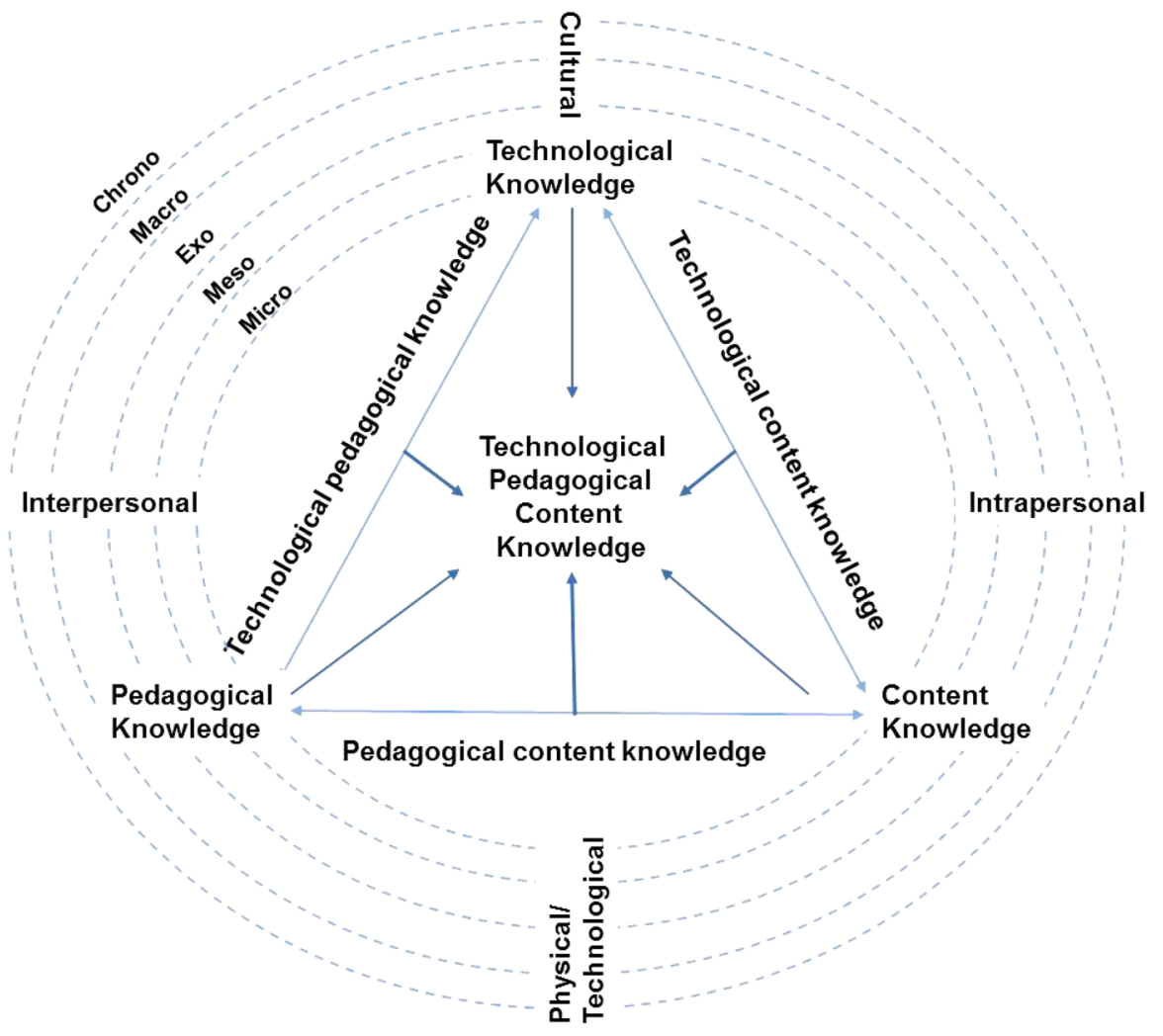

Fig. 1 Multilevel contextual TPACK

or more classrooms (i.e., the school). Thus, the educators at this level could be the principals and heads of department.

The exo-level refers to the teacher's immediate environment, and another environment that the teacher is not directly linked to such as the student's home, industry partners, research institutes, and educational bodies. Thus, at the exo-level, parents, software designers, researchers, and even ministry officers are the co-actors.

The macro-level includes the societal norms, the national policies, etc. Educators at this level include policy makers as well as media personnel.

Lastly, the chrono-level examines the change in the teacher over time, and also the change in the classroom environment. In essence, all the aforementioned educators are involved in this level as they collectively change and influence with time.

Using another example of the educational technology designer as the actor of focus, the micro-level is the classroom and the software firm. The meso-level is the relationship between the software firm and the school. The exo-level could include the relationship between the software firm and the student's home and parent, while 
the macro-level could include the Ministries of Education and Trade. Lastly, the chrono-level includes the change in the educational technology design over time.

Therefore, what our expanded TPACK framework argues is that design thinking should not rest solely on the teachers' shoulder but on all designations of educators. That is, all educators can design and create TPACK. This enables a collective effort to design and re-culture the education system and create the emergence of a new culture of learning. In other words, we envision a multilevel TPACK design effort.

\section{Research directions and conclusion}

Our proposed framework provides educational researchers with many new angles for future research on ICT integration. First, we articulate for each level of system, broad research directions that we believe could contribute to deepening the current understanding of ICT integration as framed through expanding the TPACK framework. This encourages a systematic body of research on how different levels of context shape TPACK.

Research at the micro-level has been plentiful (Voogt et al. 2013b; see also www. tpack.org). Current gaps in the research at the classroom level lie in providing vivid process data of how teachers and other educators co-design ICT-based lessons. Such research looking into the turn-by-turn collaborative design talk could help to illuminate how TPACK emerges. As for research on students, current studies are few and are limited to the humanity disciplines. For example, Schul (2010) studied the evolution of students' learning practices when they were engaged in technology supported learning of history using the activity theory. He reported that students were developing empathy for history during the intervention. More studies on students' conceptions of learning with technology, and whether their conceptions are conducive to promoting epistemic outlooks congruent with twenty-first century learning are important.

At the meso-level, principals and other school leaders can also draw on TPACK to design technologies, school-wide policies, and curricula. Studies on school leaders from a TPACK perspective are sorely lacking. One related study from the meso-level is by Jones et al. (2006). Although not explicitly written from the TPACK perspective, the study focuses on the knowledge required to design CSCL for schools and institutions. Two case studies are described: the E-QUEL network, an e-quality in e-learning network based in six different European countries, and Kaleidoscope, a European Union research network across 76 research units. The paper delineates that technology, affordance, and infrastructure are related in the design of a learning space at the meso-level. Moreover, teachers (and institutions, etc.) can only design these spaces; it is the learners who will appropriate and customize the learning environment for themselves. The authors argue for a dualist view where ICT and its affordances are separate, based on user perceptions of them. The study suggests that school leaders and designers should predict responses to design as well as prepare contingency measures.

At the exo-level, in the extant literature there is a lack of exploration of teachers' ICT integration. We suggest that the relationships between the classroom and the 
home, the classroom and researchers, and the classroom and industry partners are possible topics for research. At the macro-level, the decision makers include policy makers and the media. Policy makers design artifacts mostly in the form of policies and guidelines for their subordinate levels. Analyses of these artifacts from the framework of TPACK could reveal whether these artifacts are constructed with comprehensive consideration of all factors of TPACK, or whether they are leaning too much on a single factor. For example, policies that focus exclusively on technological affordances could be too narrow to possess ecological validity. Research of this nature is currently limited to Polly et al. (2010) study of preparing preservice teachers for ICT integration in the United States. As for media, there is a possible research question regarding the related media messages that could encourage or inhibit teachers' TPACK.

The chronosystem is associated with the sociohistorical perspective. Currently, TPACK research has rarely been pegged at this level. However, given that research in ICT integration has been around for several decades, it is possible to trace the development trajectory of specific technologies used in classrooms over time. Specific technologies possess a limited range of pedagogical affordances that may be more or less appropriate to support specific CK acquisition or creation. Tracking how associated components of TPACK develop over time would help to add an historical perspective to TPACK and ICT integration. This would allow researchers to acquire an historical sense to forecast how new forms of technologies may or may not be adopted, and the possible developmental trajectories they could have in the classroom. Such ability to formulate the grand narratives of possible historical trajectories of specific technologies, and the associated form of TPACK development at the chronosystem level could help to frame lower level design of policies.

An example which focuses on the student as the educator is a longitudinal study by Passerino and Santarosa (2008), which examined how ICT was integrated across three years for groups of autistic individuals. The specific ICT is the digital learning environment, EDUQUITO which has functions for communication, action, reflection, and follow-up. Using the sociohistorical perspective, their research showed that the participants increased their levels of social interaction such that they could be more included in school activities. Through using the ICT and interaction with other experts, the participants also learned self-regulation strategies.

Our second set of research directions concerns the inter-relationships between or across the aforementioned micro-, meso-, and exo-levels. Several researchers have examined the importance of cross level studies to examine how two or more levels interact and contradict/complement each other. Many of the extant studies do not explicitly adopt the TPACK lens. However, we provide these examples to highlight how TPACK can provide a deeper understanding of ICT integration. For example, Vavoula et al. (2009) examine the micro-, meso-, and exo-levels in the introduction of Myartspace, an application on mobile phones for inquiry-based learning. At the micro-level, the study evaluated how this ICT tool was usable for the teachers and students. At the meso-level, the study examined how the tool affected learning related to the school context. Next, the study described how this tool integrated with the museum, bridging the museum-classroom gap. This in essence is the exo-level. The study found that the tool could help extend the museum artifacts into the 
Table 1 Research directions for understanding TPACK and ICT integration with the teacher as actor

\begin{tabular}{|c|c|c|c|}
\hline Level & Educators involved & $\begin{array}{l}\text { Key research directions about } \\
\text { technology, pedagogy, and content } \\
\text { knowledge }\end{array}$ & Research foci \\
\hline $\begin{array}{l}\text { Chronosystem: } \\
\text { cultural- } \\
\text { historical }\end{array}$ & All & $\begin{array}{l}\text { How does a specific form of ICT } \\
\text { (e.g., the Internet) give rise to an } \\
\text { associated form of pedagogy } \\
\text { (e.g., Webquest) to teach content/ } \\
\text { advance content knowledge over } \\
\text { time? Are there historical } \\
\text { patterns of entry and exit for the } \\
\text { ICT? }\end{array}$ & $\begin{array}{l}\text { Historical literature } \\
\text { Review, meta- } \\
\text { analyses }\end{array}$ \\
\hline $\begin{array}{l}\text { Macrosystem: } \\
\text { international/ } \\
\text { national }\end{array}$ & Policy maker, media & $\begin{array}{l}\text { What are the common or } \\
\text { contrasting ideas (assumptions, } \\
\text { visions, mis/understandings) } \\
\text { about TPACK that are portrayed } \\
\text { in the policy papers? What are } \\
\text { the missing elements? } \\
\text { How are the curriculum guidelines } \\
\text { associated/disassociated with/ } \\
\text { from TPACK? How is TPACK } \\
\text { represented in different } \\
\text { curricula? }\end{array}$ & $\begin{array}{l}\text { International/national } \\
\text { policies analyses }\end{array}$ \\
\hline $\begin{array}{l}\text { Exosystem: } \\
\text { peripheral } \\
\text { parties }\end{array}$ & $\begin{array}{l}\text { District support staff, } \\
\text { software } \\
\text { programmer, } \\
\text { researcher, parent }\end{array}$ & $\begin{array}{l}\text { How could schools and teachers } \\
\text { work with industry partners and/ } \\
\text { or local authorities to create new } \\
\text { forms of TPACK (possibly new } \\
\text { technologies or platforms)? }\end{array}$ & $\begin{array}{l}\text { Partnerships and } \\
\text { distributed design }\end{array}$ \\
\hline $\begin{array}{l}\text { Mesosystem: } \\
\text { school }\end{array}$ & $\begin{array}{l}\text { Principal, head of } \\
\text { department }\end{array}$ & $\begin{array}{l}\text { How do school leaders create } \\
\text { school level TPACK which is } \\
\text { manifested in the policy } \\
\text { documents? What forms of } \\
\text { TPACK-related instructional } \\
\text { leadership are needed? }\end{array}$ & School policies analyses \\
\hline $\begin{array}{l}\text { Microsystems: } \\
\text { classroom }\end{array}$ & Teacher and student & $\begin{array}{l}\text { How do educators create the } \\
\text { necessary TPACK, and how does } \\
\text { the newly formed TPACK shape } \\
\text { classroom and students' learning? }\end{array}$ & Classroom processes \\
\hline Cross levels & Multiple, as above & $\begin{array}{l}\text { How is TPACK at the macro level } \\
\text { related to TPACK at the exo-, } \\
\text { meso-, and micro-levels? What } \\
\text { are the contradictions or } \\
\text { synergies of TPACK at two or } \\
\text { more levels? }\end{array}$ & $\begin{array}{l}\text { Inter-relations of } \\
\text { different educators, } \\
\text { processes, structures, } \\
\text { and policies }\end{array}$ \\
\hline
\end{tabular}

classroom context. The teacher's TPACK of designing the pre- and post-museum visits was important in helping the learners appreciate the experience and learn with the technology.

Other examples include the study by Triggs and John (2004) which explains how the "development and dissemination of professional knowledge as it relates to teaching and learning that incorporates information and communications technology" 
(p. 426) evolved and eventually transformed a community. Using the micro-, meso-, and macro-levels, the paper describes how the InterActive Education project has developed teachers' professional knowledge, and transformed the respective schools and their wider communities.

Chan (2011) reports on the micro-, meso-, and macro-levels of CSCL innovations in Hong Kong. The study emphasized the meso-context of a knowledge-building teacher network where these teachers would design and implement technological innovation projects. In addition, Zhang (2010) examines the interaction between the macro- and micro-levels in an East Asian learning culture. Macro-level elements are social values and power structures. Micro-level elements include resources and technologies, curriculum guidelines, assessment of learning, and learning tasks, activities and procedures. The author argues that ICT integration requires a principle-based rather than a procedure-based approach. This will engage teachers and allow them to deeply innovate with ICT.

As can be seen, the inter-relationships between levels provide rich insights into ICT integration. Furthermore, we posit that adopting the TPACK perspective to examine the multiple levels would provide a deeper understanding of and greater clarity in ICT integration. Table 1 indicates a summary of educators, research directions, and research foci of the different levels.

The expanded TPACK is introduced as a theoretical framework for the future consideration of creating new knowledge and innovative practices for ICT integration. This framework expands the context of TPACK in terms of actor and scope. We have broadened the notion of the teacher to all types of educators. Also, the expanded framework provides a comprehensive consideration of the different levels of influence in ICT integration based on the ecological systems theory. The framework emphasizes the multilevel collective effort for ICT integration. In line with our conception of ICT as a design tool, we argue that design thinking needs to permeate the education system for all key education stakeholders.

\section{References}

Baytak, A., \& Land, S. M. (2011). An investigation of the artifacts and process of constructing computers games about environmental science in a fifth grade classroom. Educational Technology Research \& Development, 59, 765-782.

Bereiter, C., \& Scardamalia, M. (2006). Education for the knowledge age. In P. A. Alexander \& P. H. Winne (Eds.), Handbook of educational psychology (2nd ed., pp. 695-713). Mahwah, NJ: Lawrence Erlbaum.

Blackwell, C. K., Lauricella, A. R., Wartella, E., Robb, M., \& Schomburg, R. (2013). Adoption and use of technology in early education: The interplay of extrinsic barriers and teacher attitudes. Computers \& Education, 69, 310-319. doi:10.1016/j.compedu.2013.07.024.

Bronfenbrenner, U. (1994). Ecological models of human development. In T. Husen \& T. N. Postlethwaite (Eds.), International encyclopedia of education (2nd ed., Vol. 3, pp. 1643-1647). Oxford: Pergamon Press.

Bronfenbrenner, U. (Ed.). (2005). Making human beings human: Bioecological perspectives on human development. Thousand Oaks, CA: Sage. 
Chai, C. S. (2010). The relationships between Singaporean preservice teachers' ICT competencies, pedagogical beliefs and their beliefs on the espoused use of ICT. The Asia-Pacific Education Researcher, 19(3), 387-400.

Chai, C. S., Koh, J. H. L., \& Tsai, C.-C. (2013). A review of Technological Pedagogical Content Knowledge. Education Technology and Society, 16(2), 31-51.

Chai, C. S., Koh, J. H. L., Tsai, C.-C., \& Tan, L. (2011). Modeling primary school pre-service teachers' Technological Pedagogical Content Knowledge (TPACK) for meaningful learning with information and communication technology (ICT). Computers \& Education, 57, 1184-1193.

Chai, C. S., \& Lim, C. P. (2011). The internet and teacher education: Traversing between the digitized world and schools. The Internet and Higher Education, 14, 3-9.

Chan, C. K. (2011). Bridging research and practice: Implementing and sustaining knowledge building in Hong Kong classrooms. International Journal of Computer-Supported Collaborative Learning, 6(2), $147-186$.

Cox, S., \& Graham, C. R. (2009). Diagramming TPACK in practice: Using an elaborated model of the TPACK framework to analyze and depict teacher knowledge. TechTrends: Linking Research \& Practice to Improve Learning, 53(5), 60-69. doi:10.1007/s11528-009-0327-1.

Cross, N. (2006). Designerly ways of knowing. Boston, MA: Birkhauser.

Dodge, B. (2001). FOCUS: Five rules for writing great WebQuests. Learning \& Leading with Technology, 28(8). http://webquest.sdsu.edu/focus/focus.pdf.

Engestrom, Y. (1999). Activity theory and individual and social transformation. In Y. Engestrom, R. Miettinen, \& R. L. Punamaki (Eds.), Perspectives on activity theory (pp. 19-38). Cambridge: Cambridge University Press.

Ertmer, P. A. (1999). Addressing first- and second-order barriers to change: Strategies for technology integration. Educational Technology Research and Development, 47(4), 47-61.

Ertmer, P. A. (2005). Teacher pedagogical beliefs: The final frontier in our quest for technology integration. Educational Technology Research \& Development, 53(4), 25-39.

Facer, K. (2011). Learning future: Education, technology and social change. New York, NY: Routledge.

Goktas, Y., Gedik, N., \& Baydas, O. (2013). Enablers and barriers to the use of ICT in primary schools in Turkey: A comparative study of 2005-2011. Computers \& Education, 68, 211-222.

Hsu, S., \& Kuan, P.-Y. (2013). The impact of multilevel factors on technology integration: The case of Taiwanese grade 1-9 teachers and schools. Educational Technology Research \& Development, 61(1), 25-50.

Jamieson-Proctor, R. M., Burnett, P. C., Finger, G., \& Glenice Watson, G. (2006). ICT integration and teachers' confidence in using ICT for teaching and learning in Queensland state schools. Australasian Journal of Educational Technology, 22(4), 511-530.

Jonassen, D. H. (2000). Computers as mindtools for schools. Upper Saddle River, NJ: Merrill.

Jonassen, D. H., Howland, J., Marra, R., \& Crismond, D. (2008). Meaningful learning with technology (3rd ed.). Upper Saddle River, NJ: Pearson.

Jones, C., Dirckinck-Holmfeld, L., \& Lindström, B. (2006). A relational, indirect, meso-level approach to CSCL design in the next decade. International Journal of Computer-Supported Collaborative Learning, 1(1), 35-56.

Koehler, M. J., \& Mishra, P. (2009). What is Technological Pedagogical Content Knowledge? Contemporary Issues in Technology and Teacher Education (CITE Journal), 9(1), 60-70.

Koh, J. H. L., Chai, C. S., \& Tsai, C. C. (2013). Examining practicing teachers' perceptions of Technological Pedagogical Content Knowledge (TPACK) pathways: A structural equation modeling approach. Instructional Science, 41(4), 793-809.

Lim, C. P. (2006). The science and art of integrating ICT in Singapore schools. Singapore: IT21 Pte Ltd.

Lim, C. P. (2007). Effective integration of ICT in Singapore schools: Pedagogical and policy implications. Educational Technology Research and Development, 55(1), 83-116.

Lim, C. P., \& Chai, C. S. (2008). Teachers' pedagogical beliefs and their planning and conduct of computer-mediated classroom lessons. British Journal of Educational Technology, 39(5), 807-828.

Lim, C. P., \& Hang, D. (2003). An activity theory approach to research of ICT integration in Singapore schools. Computers \& Education, 41, 49-63.

Lim, C. P., Zhao, Y., Tondeur, J., Chai, C.-S., \& Tsai, C.-C. (2013). Bridging the gap: Technology trends and use of technology in schools. Educational Technology \& Society, 16(2), 59-68.

Macdonald, G., \& Hursh, D. (2006). Twenty-first century schools: Knowledge, networks and new economies. Rotterdam: Sense Publication. 
Mishra, P., \& Koehler, M. J. (2006). Technological Pedagogical Content Knowledge: A framework for teacher knowledge. Teachers College Record, 108(6), 1017-1054.

Passerino, L. M., \& Santarosa, L. M. C. (2008). Autism and digital learning environments: Processes of interaction and mediation. Computers \& Education, 51(1), 385-402.

Pelgrum, W. J. (2001). Obstacles to the integration of ICT in education: Results from a worldwide educational assessment. Computers \& Education, 37, 163-178.

Polly, D., Mims, C., Shepherd, C. E., \& Inan, F. (2010). Evidence of impact: Transforming teacher education with Preparing Tomorrow's Teachers to Teach with Technology (PT3) Grants. Teaching and Teacher Education: An International Journal of Research and Studies, 26(4), 863-870.

Porras-Hernandez, L. H., \& Salinas-Amescua, B. (2013). Strengthening TPACK: A broader notion of context and the use of teacher's narratives to reveal knowledge construction. Journal of Educational Computing Research, 48(2), 223-244.

Sandholtz, J. H., \& Reilly, B. (2004). Teachers, not technicians: Rethinking technical expectations for teachers. Teachers College Record, 106(3), 487-512.

Sang, G., Valcke, M., van Braak, J., \& Tondeur, J. (2010). Student teachers' thinking processes and ICT integration: Predictors of prospective teaching behaviors with educational technology. Computers \& Education, 54(1), 103-112.

Schul, J. E. (2010). Necessity is the mother of invention: An experienced history teacher's integration of desktop documentary making. International Journal of Technology in Teaching \& Learning, 6(1), 14-32.

Shulman, L. S. (1986). Those who understand: Knowledge growth in teaching. Educational Researcher, 15(2), 4-14. doi:10.3102/0013189x015002004.

Shulman, L. S. (1987). Knowledge and teaching: Foundations of the new reform. Harvard Educational Review, 57(1), 1-22.

Taylor, R. P. (1980). Introduction. In: R. P. Taylor (Ed.), The computer in the school: Tutor, tool, tutee. (p. 1-10). New York, NY: Teachers College Press. Available from: http://www.citejournal.org/ articles/v3i2seminal1.pdf.

Thomas, D., \& Brown, J. S. (2011). A new culture of learning: Cultivating the imagination for a world of constant change. Lexington, KY: CreateSpace.

Tondeur, J., Van Keer, H., van Braak, J., \& Valcke, M. (2008). ICT integration in the classroom: Challenging the potential of a school policy. Computers \& Education, 51, 212-223.

Triggs, P., \& John, P. (2004). From transaction to transformation: Information and communication technology, professional development and the formation of communities of practice. Journal of Computer Assisted learning, 20(6), 426-439.

Tsai, C.-C. (2004). Beyond cognitive and metacognitive tools: The use of the Internet as an "epistemological" tool for instruction. British Journal of Educational Technology, 35, 525-536.

Tsai, C.-C., \& Chai, C. S. (2012). The "third"-order barrier for technology-integration instruction: Implications for teacher education. Australasia Journal of Education Technology, 28(6), 1057-1060.

Tsai, C.-C., Chai, C. S., Wong, B., Hong, H.-Y., \& Tan, S. C. (2013). Positioning design epistemology and its applications in education technology. Educational Technology and Society, 16(2), 81-90.

Vavoula, G., Sharples, M., Rudman, P., Meek, J., \& Lonsdale, P. (2009). Myartspace: Design and evaluation of support for learning with multimedia phones between classrooms and museums. Computers \& Education, 53(2), 286-299.

Voogt, J., Estrad, O., Dede, C., \& Mishra, P. (2013a). Challenges to learning and schooling in the digital networked world of the 21st century. Journal of Computer Assisted learning, 29, 403-413.

Voogt, J., Fisser, P., Pareja Roblin, N., Tondeur, J., \& van Braak, J. (2013b). Technological Pedagogical Content Knowledge-a review of the literature. Journal of Computer Assisted learning, 29(2), $109-121$.

Voogt, J., Knezek, G., Cox, M., Knezek, D., \& Brummelhuis, A. (2013c). Under which conditions does ICT have a positive effect on teaching and learning? A call to action. Journal of Computer Assisted learning, 29(1), 4-14.

Voogt, J., \& Roblin, N. P. (2012). A comparative analysis of international frameworks for 21st century competences: Implications for national curriculum policies. Journal of Curriculum Studies, 44, 299-321.

Zhang, J. (2010). Technology-supported learning innovation in cultural contexts. Educational Technology Research and Development, 58(2), 229-243. 
Zhao, Y., Pugh, K., Sheldon, S., \& Byers, J. L. (2002). Conditions for classroom technology innovations. Teacher College Record, 104(3), 482-515.

Ching Sing Chai is an associate professor at the National Institute of Education, Nanyang Technological University. His research interest is in the field of teachers' beliefs, Technological Pedagogical Content Knowledge and computer-supported collaborative learning. For the past decades, he has been actively involved in numerous funded research projects and published widely in educational technology journals.

Elizabeth Koh is a Research Scientist with the Office of Education Research, National Institute of Education (NIE), Singapore. Her research interests are in education and IT specifically collaboration and other 21 st century learner competencies. She has a Ph.D. in Information Systems from the National University of Singapore. She is currently a principal investigator of two NIE Education Funding projects. She has published in Computers \& Education and IEEE Transactions on Professional Communication among other peerreviewed journals.

Cher Ping LIM is a Professor of Curriculum and Innovations, and the Director of the Centre for Learning, Teaching and Technology at the Hong Kong Institute of Education. In the last 10 years, he has been the principal investigator of several major and high impact research projects in Australia, Hong Kong, Indonesia and Singapore. To date, Professor Lim has provided technical consultancy services to UNESCO, Inter-American Development Bank, Asian Development Bank, World Bank, World Links, Microsoft, universities, schools and governments in the areas for teacher professional development, education policies, and assessments. He has published internationally in different areas of education technologies, namely learning engagement, emerging technologies and global citizenship, and evolving curriculum and assessment in teacher education.

Chin-Chung Tsai holds a B.Sc. in physics from National Taiwan Normal University. He received a Master of Education degree from Harvard University and completed his doctoral study at Teachers College, Columbia University in 1996. From 1996 to 2006, he joined the faculty of Center for Teacher Education and Institute of Education, National Chiao Tung University, Hsinchu, Taiwan. He is currently a Chair Professor at the Graduate Institute of Digital Learning and Education, National Taiwan University of Science and Technology, Taipei, Taiwan. Since July 2009, he has been appointed as the Co-Editor of Computers \& Education. His research interests deal largely with constructivism, epistemological beliefs, and Internet-based instruction related to science education. 